\section{Efficacy and Persistence of Paclobutrazol Applied to Rooted Cuttings of Rhododendron Before Transplant}

\author{
Martin P.N. Gent ${ }^{1}$ \\ Department of Forestryand Horticulture, Connecticut Agricultural Experiment \\ Station, P.O. Box 1106, New Haven, CT 06504
}

Additional index words. growth retardant, persistence, stem elongation

\begin{abstract}
Efficacy of paclobutrazol was determined when applied to rooted cuttings before transplant. Cuttings of large-leaf Rhododendron catawbiense Michx. were treated with paclobutrazol applied as a 40-mL drench. In 1998, concentrations of $0,1,2,10$, or 20 $\mathrm{mg} \cdot \mathrm{L}^{-1}$ were applied to liners before root development was complete in February, or after cuttings were root-bound in May. The same volume of solution was applied to other plants at concentrations of $0,5,10$, or $20 \mathrm{mg} \cdot \mathrm{L}^{-1}$ in July 1998, after transplant to 1-gal pots. In 1999 , a $40-\mathrm{mL}$ drench of paclobutrazol at $0,1,2,5,10$, or $20 \mathrm{mg} \cdot \mathrm{L}^{-1}$ was only applied to liners in April. All cuttings were transplanted to 1-gal pots and set in the field. The elongation of stems was measured after each of three flushes of growth. Plants were far more responsive to paclobutrazol when it was applied before, rather than after transplant. There was a saturating response to paclobutrazol concentration and the half-maximal response occurred at 2 to $4 \mathrm{mg} \cdot \mathrm{L}^{-1}(0.08$ to $0.16 \mathrm{mg} / \mathrm{plant})$. At low rates, later flushes of growth were affected less than earlier flushes. However if paclobutrazol was applied at 10 or $20 \mathrm{mg} \cdot \mathrm{L}^{-1}$, later flushes of growth were inhibited more completely than early flushes. Flowering was enhanced by paclobutrazol. Paclobutrazol at $2 \mathrm{mg} \cdot \mathrm{L}^{-1}$ applied to rooted cuttings before transplant was sufficient to inhibit growth of rhododendron, but not to the point where later flushes of growth were excessively short. Chemical name used: $2 R S, 3 R S-1$-(4-chlorophenyl)-4,4-dimethyl-2-(1,2,4-triazol-l-yl)-pentan-3-ol (paclobutrazol).
\end{abstract}

Paclobutrazol is a triazole growth regulator that inhibits stem elongation and promotes flowering of field-grown rhododendron (Gent, 1995; Ranney et al., 1994; Wilkinson and Richards, 1991). The response to concentration of paclobutrazol varied among these studies. Wilkinson and Richards (1991) found paclobutrazol applied as a spray to the point of runoff drastically inhibited stem elongation for more than a year only if the concentrations were $>500 \mathrm{mg} \cdot \mathrm{L}^{-1}$. Ranney et al. (1994) noted sprays with concentrations $\leq 200 \mathrm{mg} \cdot \mathrm{L}^{-1}$ had little effect on stem elongation and no effect on flower number, but there was a strong response to a $355-\mathrm{mL}$ drench that appeared to saturate at $20 \mathrm{mg} \cdot \mathrm{L}^{-1}$ (a 7 - $\mathrm{mg}$ dose per plant). There was a linear response of flower number to concentration. However, Gent $(1995,1997)$ found that stem elongation was limited to half that of the control with a spray or a drench at doses as low as $2.2 \mathrm{mg} /$ plant. An increase in flowering was noted at doses as low as 0.4 $\mathrm{mg} /$ plant. Factors that may account for these differences in response to dose or concentration of paclobutrazol are plant size or development, environment, cultivar, and potting medium. More consistent results might be obtained by treating cuttings before transplant, when they are a well-defined size and growing under con-

Received for publication 22 Apr. 2002. Accepted for publication 19 Feb. 2003. This research was conducted in collaboration with Barbara Kolnsberg, formerly of Imperial Nurseries, Granby, Conn. Imperial Nurseries donated the plant material for these experiments. I thank Michael Short for technical assistance.

${ }^{1}$ E-mail address: Martin.Gent@po.state.ct.us trolled conditions. However, it is not clear how long such a treatment would last, or what is the appropriate dose for such small plants.

Growth of bedding plants and herbaceous perennials is inhibited for only a few weeks when treated with triazole growth retardant before transplanting. Growth of geranium was inhibited for 4 weeks by a spray application of paclobutrazol at $7 \mathrm{mg} \cdot \mathrm{L}^{-1}$ (Latimer and Baden, 1992), or uniconazole at $10 \mathrm{mg} \cdot \mathrm{L}^{-1}$ (Keever and Foster, 1991), but plant size was similar to controls after 6 or 8 weeks, respectively. Growth of chrysanthemum was inhibited for 8 weeks after cuttings were dipped in a solution of uniconazole at $10 \mathrm{mg} \cdot \mathrm{L}^{-1}$ before transplant, but growth recovered by 11 weeks (Schuch, 1994). Triazole growth retardants have a more persistent effect on woody perennial plants. Six species treated with either a spray or drench of uniconazole were smaller than controls $100 \mathrm{~d}$ after application (Warren et al., 1991). Adrench of paclobutrazol at $25 \mathrm{mg} /$ plant inhibited stem elongation of grapevine by $50 \%$ or more for a year (Reynolds and Wardle, 1990). A similar long-term inhibition of stem elongation was observed for rhododendron after a treatment with a drench of paclobutrazol at doses of 7 or 50 mg/plant (Ranney et al., 1994; Wilkinson and Richards, 1992). A spray application with a dose of $20 \mathrm{mg} /$ plant inhibited the growth of one cultivar of rhododendron for 2 years after application (Gent, 1997).

Models have been developed to predict the persistence of the effect of growth retardants. Amodified inverse relation (Dicks and Charles Edwards, 1973) related the inhibition of stem elongation to the concentration of dami- nozide in the stem of chrysanthemum. The concentration was presumed to decrease due to plant growth and dilution by new biomass. A power of the inverse relation accounted for the dependence of leaf elongation of Cyperus on the concentration of paclobutrazol (Kawabata and DeFrank, 1994). Daily measurements of growth of poinsettia showed that growth recovered in 15 to $45 \mathrm{~d}$ after application of chlormequat as a spray at 500 to $4000 \mathrm{mg} \cdot \mathrm{L}^{-1}$ (Fisher et al., 1996). The time for growth to recover to the rate of controls was proportional to growth retardant concentration. A similar time period was noted for recovery of growth of chrysanthemum from either a spray or drench application of uniconazole (Tayama and Carver, 1992). To estimate the recovery of growth of rhododendron after application of triazoles, an exponential decay with time was incorporated into the coefficient for the inverse relation of stem elongation to initial concentration of growth retardant (Gent 1997). The time constant found by this method was about two per year, equivalent to lowering the apparent growth retardant concentration in the plant by a factor of seven in 1 year. Thus, the effects of treating rooted cuttings of rhododendron with paclobutrazol may last over an entire growing season, or longer.

The efficacy of growth retardant depends on the method of application (Gent and McAvoy, 2000). Adrench is generally more efficient than a spray or other methods of incorporation into root medium (Sanderson et al., 1988). However, pine bark appears to lower the efficacy of triazole growth retardants applied as a drench (Barrett, 1982, Million et al., 1998). Paclobutrazol binds strongly to pine bark, confining it to the upper layer of medium when applied as a drench (Million et al., 1999). Poinsettia and chrysanthemum responded linearly to low doses of uniconazole when applied as root dips before transplant (Bearce and Singha 1992, Schuch 1994), while a drench application after transplant into pine-bark medium was less effective (Newman and Tant, 1995). Pine bark is a popular constituent of potting mixes for propagation of rhododendron. An application of growth regulator before transplant may avert any problems due to binding of chemical to a large volume of root medium.

This report describes the inhibition of stem elongation of rhododendron after drench application of paclobutrazol to rooted cuttings before transplant. The concentration and time dependence of application are reported for four cultivars.

\section{Materials and Methods}

Plant material and growth conditions. In Nov. 1997 or Nov. 1998, cuttings of the large-leaf $R$. catawbiense cultivars Boursault, Nova zembla, Roseum elegans, and Rhododendron Cunninghams white were rooted in in peat-based medium in a heated greenhouse at a commercial nursery (Imperial Nurseries, Granby, Conn). Six months later in May, the rooted cuttings were moved to the experimental farm of the Connecticut Agricultural Experiment Station in Hamden, and transplanted into 
1-gal black-poly pots that contained 2.6 L of a mix of 32 hardwood bark : 32 softwood bark : 32 peat : 5 sand $(\mathrm{v} / \mathrm{v})$. The pots were set at a close spacing on black weed barrier cloth in an open field. Pots were grouped into subplots of five plants for each combination of application date $\times$ concentration $\times$ cultivar. There were two replicate sub-plots of five plants in 1998 and four replicates in 1999, in a randomized complete-block design. At 1- or 2-d intervals, plants were watered from overhead at $0800 \mathrm{HR}$, and fertilized once with with $15 \mathrm{~g}$ of a 5-month timed-release formulation of $24 \mathrm{~N}-4 \mathrm{P}_{2} \mathrm{O}_{5}-8 \mathrm{~K}_{2} \mathrm{O}$ with minor elements (Osmocote Pro, Scotts, Maryville, Ohio).

Application of growth regulators. Paclobutrazol in the Bonzi formulation (Uniroyal Chemical Co., Naugatuck, Conn.) was applied as a root medium drench of $40 \mathrm{~mL} /$ plant. This volume was sufficient to saturate the volume of root medium in the liners used to establish cuttings. An equal volume of water was applied to controls. In 1998, plants were treated only once, on one of three dates. On 24 Feb. and 19 May, the treatments were applied to the liners in the heated greenhouse before transplanting. A proportioner was used to dilute paclobutrazol to concentrations of $0,1,2,10$, or $20 \mathrm{mg} \cdot \mathrm{L}^{-1}$. Plants were treated from highest to lowest concentration, with a 20-s flush of hoses between treatments. Other plants were treated on 28 July, after transplant to 1-gal pots. Solutions were pre-diluted to paclobutrazol concentrations of $0,5,10$, and $20 \mathrm{mg} \cdot \mathrm{L}^{-1}$ and $40 \mathrm{~mL}$ was applied to each pot. In 1999, paclobutrazol was applied only on $26 \mathrm{Apr}$. Flats of rooted cuttings were drenched with pre-diluted solutions of paclobutrazol at concentrations of $0,1,2,5$, 10 , and $20 \mathrm{mg} \cdot \mathrm{L}^{-1}$.

Measurements. In Apr. 1998, and after each flush of growth, three stems on each plant were marked with white paint just below the terminal bud. Stem elongation was measured for three stems after each flush of growth by measuring the distance from this mark to the base of the terminal bud for the tallest stems on a plant. The number of apexes (stems) and the number of flower buds were counted in October. In 1999, internode elongation was determined by measuring the distance from the wood of the original cutting to the base of the terminal buds on three stems. In both years, measurements in October were compared to measurements of the same plants taken earlier, to check for correct assignment of each flush of growth. In many instances, the internode length in October was 1 or $2 \mathrm{~cm}$ longer than when it was measured at or just after elongation. The foliage had hardened off in October, and there was no further growth.

In 1998, a sample of 10 untreated plants of each cultivar was harvested on each treatment date to determine biomass at the time of treatment. Plants were separated into leaf, stem, and root, dried and weighed. In Nov. 1998, five plants of each treatment and cultivar were cut off at the soil line. Leaves and stems were separated, number and area of leaves was measured, and parts were dried for $72 \mathrm{~h}$ at 80 ${ }^{\circ} \mathrm{C}$ then weighed.

Analysis. SYSTAT (Version 6, SPSS,
Chicago) was used for analysis of variance of the randomized complete-block design. Date of application and cultivar were included as categorical variables and concentration was included as a numerical variable with linear and quadratic components. In 1998, there were four cultivars, three treatment dates, and four or five concentrations applied on each date, with two replicate blocks. In 1999, there were four cultivars and six concentrations applied on one date, with four replicate blocks. Stem elongation for a particular application date and cultivar was fit to an inverse function of concentration [Eq. 1] to determine $\mathrm{K}_{\mathrm{C}}$, in units of $\mathrm{mg} \cdot \mathrm{L}^{-1}$, the dose required to inhibit stem elongation to half that observed for control plants. Elongation
concentration $)=$$\frac{\text { Control elongation } \times \mathrm{K}_{\mathrm{C}}}{\mathrm{K}_{\mathrm{C}}+\text { concentration }}$

The SOLVER algorithm in EXCEL (version 97, Microsoft Corp. Redmond, Wash.) was used to minimize the sum of squares difference between this inverse model and the data.

\section{Results}

Treatments in 1998: Stem elongation. Cultivar, date of application, and linear and quadratic terms in concentration, affected internode elongation to a drench of paclobutrazol in 1998 (Table 1). Differences among cultivars are discussed later. Paclobutrazol applied at $20 \mathrm{mg} \cdot \mathrm{L}^{-1}$ in February resulted in the shortest plants of all the treatments, but for all other concentrations, an application in May was more effective than in February (Fig. 1). Whereas untreated plants grew about $16 \mathrm{~cm}$, plants grew only $11 \mathrm{~cm}$ if treated in May with paclobutrazol solution as dilute as $2 \mathrm{mg} \cdot \mathrm{L}^{-1}$.

Table 1. Significance of factors affecting the response of internode elongation, and total number of stems and flowers of rhododendron to a drench application of paclobutrazol in 1998.

\begin{tabular}{|c|c|c|c|c|c|c|}
\hline \multirow[b]{2}{*}{ Factor } & \multirow[b]{2}{*}{ Flush no.: } & \multicolumn{3}{|c|}{ Internode length } & \multicolumn{2}{|c|}{ No. of } \\
\hline & & 1 & 2 & 3 & Stems & Flowers \\
\hline Cultivar & & $0.000^{\mathrm{z}}$ & 0.004 & 0.000 & 0.000 & NS \\
\hline Treatment date (Date) & & NS & 0.000 & 0.001 & NS & 0.000 \\
\hline Concn $(\mathrm{L})^{\mathrm{y}}$ & & NS & 0.000 & 0.000 & NS & NS \\
\hline Concn $\times$ Concn $(\mathrm{Q})$ & & NS & NS & NS & NS & NS \\
\hline Cultivar $\times$ Date & & 0.000 & 0.001 & 0.002 & NS & 0.000 \\
\hline Cultivar $\times$ L & & NS & NS & 0.006 & NS & NS \\
\hline Cultivar $\times \mathrm{Q}$ & & NS & NS & NS & NS & NS \\
\hline Date $\times \mathrm{L}$ & & 0.006 & 0.000 & 0.000 & NS & 0.008 \\
\hline Date $\times Q$ & & 0.031 & 0.000 & 0.000 & NS & NS \\
\hline Cultivar $\times$ Date $\times \mathrm{L}$ & & NS & NS & 0.003 & 0.002 & 0.004 \\
\hline Cultivar $\times$ Date $\times Q$ & & NS & NS & 0.003 & 0.002 & 0.006 \\
\hline
\end{tabular}

${ }^{2}$ Probability that factor has no effect; ns indicates $P>0.05$.

${ }^{\mathrm{y}} \mathrm{L}, \mathrm{Q}$, linear and quadratic effects of concentration.

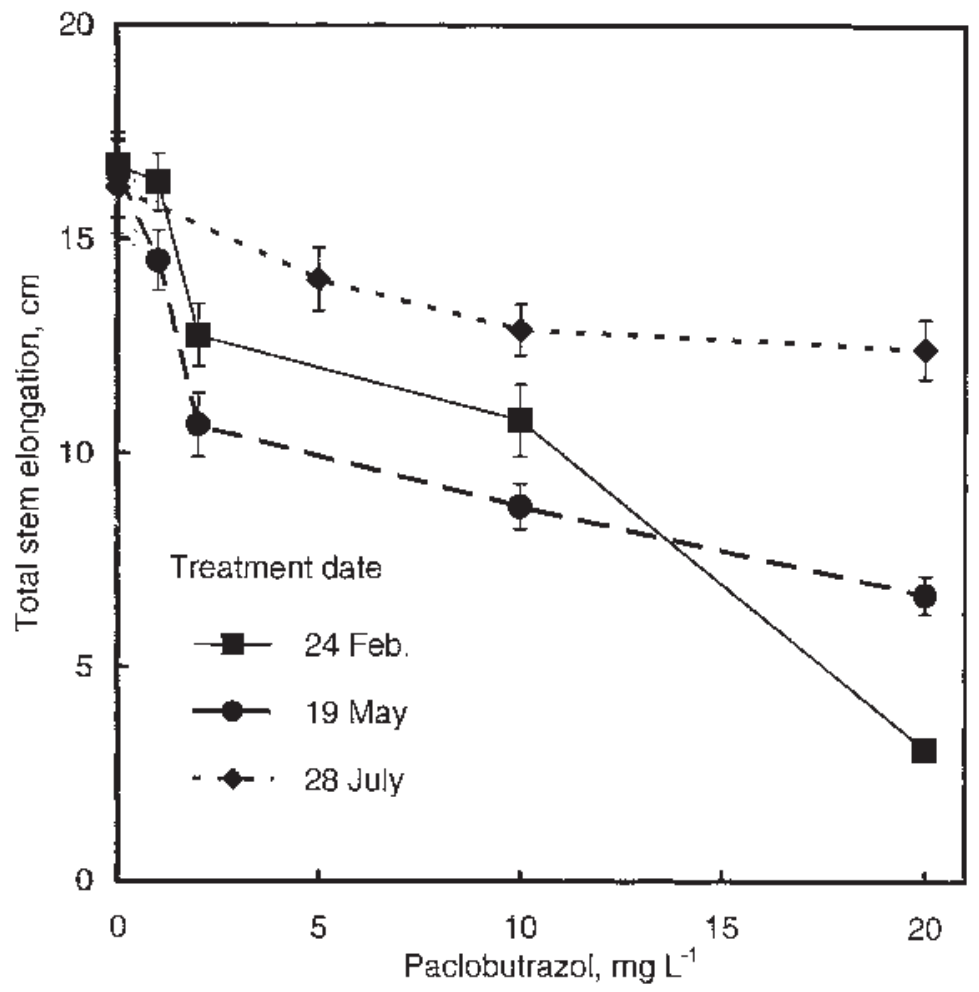

Fig. 1. Total stem elongation of rhododendron in 1998 as a function of paclobutrazol concentration and application date. Symbols are averages over four cultivars, and error bars indicate standard error of estimate from analysis of variance. 
Response to concentration of paclobutrazol was nonlinear, and this concentration-dependent response varied among application dates. Application in July had much less effect than earlier applications.

Paclobutrazol affected each flush of growth after application. The first flush of growth occurred in mid to late Apr. 1998. If applied in February, paclobutrazol inhibited this flush of growth at concentrations as low as $2 \mathrm{mg} \cdot \mathrm{L}^{-1}$ (Fig. 2). The second flush of growth was complete by late June, and the third flush grew from early August to mid-September. Both the second and third flushes were inhibited by paclobutrazol at $2 \mathrm{mg} \cdot \mathrm{L}^{-1}$ if it was applied in May. The second and third flushes of growth were more inhibited by paclobutrazol at 10 and $20 \mathrm{mg} \cdot \mathrm{L}^{-1}$ if it was applied in May, rather than February. However, the first flush of growth occurred prior to application in May, so total stem elongation was shortest for the $20 \mathrm{mg} \cdot \mathrm{L}^{-1}$ application in February. There was little elongation of the third flush after application of paclobutrazol at $20 \mathrm{mg} \cdot \mathrm{L}^{-1}$ in February, or 10 or $20 \mathrm{mg} \cdot \mathrm{L}^{-1}$ in May. These rates inhibited the third flush of growth when applied on 28 July, but to a much lesser extent than when applied in May. The July treatment was applied to 1-gal pots, but the volume of solution used to drench the pots was the same as earlier applications.

Adifference in biomass could explain why responses differed by application date. Leaf, stem, and root weights around the time of each application are shown in Table 3. Most of the gain in dry weight gain occurred during the third flush of growth, after the July application. Root weight changed more than shoot weight between March and May. Thus, the response to application in February may have differed from that in May due to improved root development and more efficient uptake of the growth retardant in May. Biomass in July was twice that in May. As of Nov. 1998, leaf weight and leaf area were not affected by paclobutrazol, excepting applications in February or May at $20 \mathrm{mg} \cdot \mathrm{L}^{-1}$ lowered average leaf weight from 30 to $24 \mathrm{~g}$ (data not shown). The main effect of paclobutrazol was on stem weight, which ranged from 4 to $12 \mathrm{~g}$, depending on concentration and date of application

Effect on number of flower buds. The plants treated in February had $\approx 1$ to 3 flower buds at the end of the season, and there was no significant response of flower number to paclobutrazol (data not shown). If applied in May, paclobutrazol increased the number of flower buds significantly, from $\approx 1$ to 3 or 4 buds per plant treated with $20 \mathrm{mg} \cdot \mathrm{L}^{-1}$. The cultivar Cunninghams white had more flower buds than the other cultivars without treatment. Some of the 'Cunninghams white' flowered prematurely in Fall 1998 if treated with paclobutrazol at $20 \mathrm{mg} \cdot \mathrm{L}^{-1}$. In most cases only a single floret opened on the raceme. The cohort of plants treated in July was pruned at Imperial Nursery before transplant, and no flower buds developed on these plants. The significance of the three-way interactions noted in Table 1 derives from this pruning.

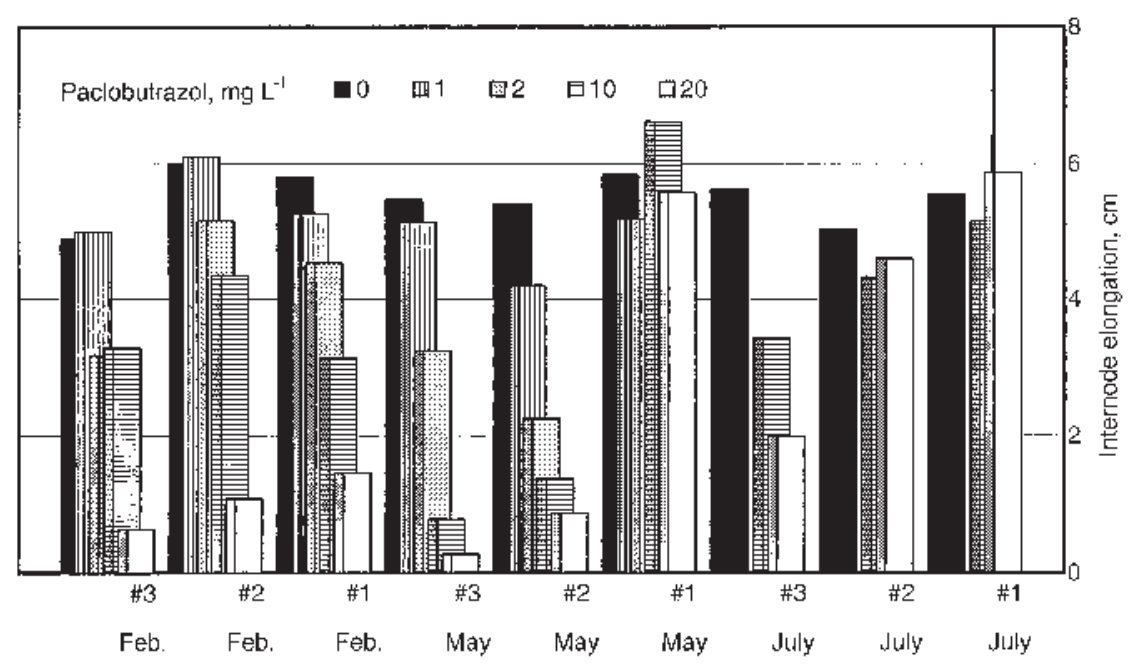

Flush of growth / Appligation date

Fig. 2. Elongation of each flush of growth of rhododendron in 1998 as affected by paclobutrazol concentration within each application date. Bars are elongation averaged over four cultivars and grouped by flush of growth within application date. Shading, or depth within the chart, indicates concentration of paclobutrazol.

Table 2. Significance of factors affecting the response of internode and total stem elongation, and number of flowers of rhododendron to a drench application of paclobutrazol in 1999.

\begin{tabular}{|c|c|c|c|c|c|c|}
\hline \multirow[b]{2}{*}{ Factor } & \multirow[b]{2}{*}{ Flush no.: } & \multicolumn{3}{|c|}{ Internode length } & \multirow{2}{*}{$\begin{array}{l}\text { Total stem } \\
\text { elongation }\end{array}$} & \multirow{2}{*}{$\begin{array}{l}\text { No. of } \\
\text { flowers }\end{array}$} \\
\hline & & 1 & 2 & 3 & & \\
\hline$\overline{\text { Cultivar }}$ & & $0.000^{\mathrm{z}}$ & 0.053 & 0.000 & 0.000 & 0.000 \\
\hline Concentration $(\mathrm{L})^{\mathrm{y}}$ & & 0.000 & 0.000 & 0.000 & 0.000 & 0.000 \\
\hline Concn $\times$ Concn $(Q)$ & & 0.000 & 0.000 & 0.000 & 0.000 & 0.000 \\
\hline Cultivar $\times \mathrm{L}$ & & NS & 0.017 & 0.019 & NS & 0.000 \\
\hline Cultivar $\times \mathrm{Q}$ & & NS & 0.023 & NS & NS & 0.000 \\
\hline
\end{tabular}

${ }^{2}$ Probability that factor has no effect; NS indicates $P>0.05$.

${ }^{\mathrm{y}} \mathrm{L}, \mathrm{Q}$, linear and quadratic effects of concentration.

Table 3. Dry weight of rhododendron harvested on three application dates, and the end of the growing season in 1998.

\begin{tabular}{llrrr}
\hline & & \multicolumn{3}{c}{ Dry wt (g) } \\
\cline { 3 - 5 } Date & \multicolumn{1}{c}{ Cultivar } & Leaf & Stem & Root \\
\hline 1 Mar. & Boursault & 2.3 & 1.5 & 1.7 \\
& Cunninghams white & 2.0 & 1.3 & 1.2 \\
& Nova zembla & 3.9 & 2.3 & 2.5 \\
Average & Roseum elegans & 3.0 & 2.3 & 4.6 \\
20 May & Boursault & 2.8 & 1.8 & 2.5 \\
& Cunninghams white & 2.8 & 1.7 & 2.7 \\
& Nova zembla & 5.0 & 3.2 & 4.5 \\
Average & Roseum elegans & 3.5 & 3.1 & 3.9 \\
25 July & Boursault & 3.7 & 2.5 & 3.9 \\
& Cunninghams white & 9.7 & 5.3 & 6.3 \\
& Nova zembla & 6.7 & 5.6 & 8.7 \\
& Roseum elegans & 12.5 & 5.3 & 10.0 \\
Average & & 8.8 & 6.5 & 7.6 \\
1 Nov. & Boursault & 38.3 & 12.1 & 8.1 \\
& Cunninghams white & 20.8 & 10.6 & --- \\
& Nova zembla & 21.9 & 9.2 & --- \\
& Roseum elegans & 36.3 & 13.4 & --- \\
Average & & 30.2 & 11.5 & --- \\
\hline & & & &
\end{tabular}




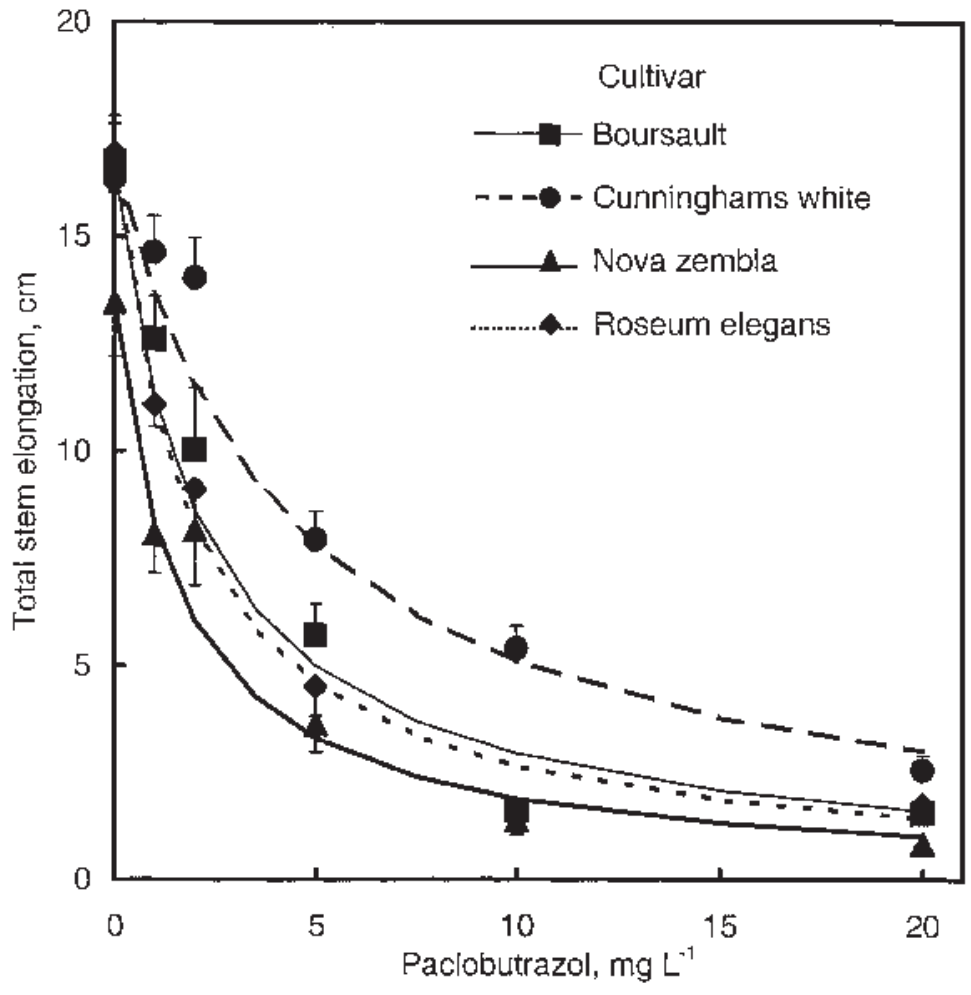

Fig. 3. Total stem elongation of rhododendron in 1999 as a function of paclobutrazol concentration. Symbols represent each of four cultivars, error bars indicate standard error of estimate, and lines indicate the prediction of [Eq. 1] fit to each cultivar individually.

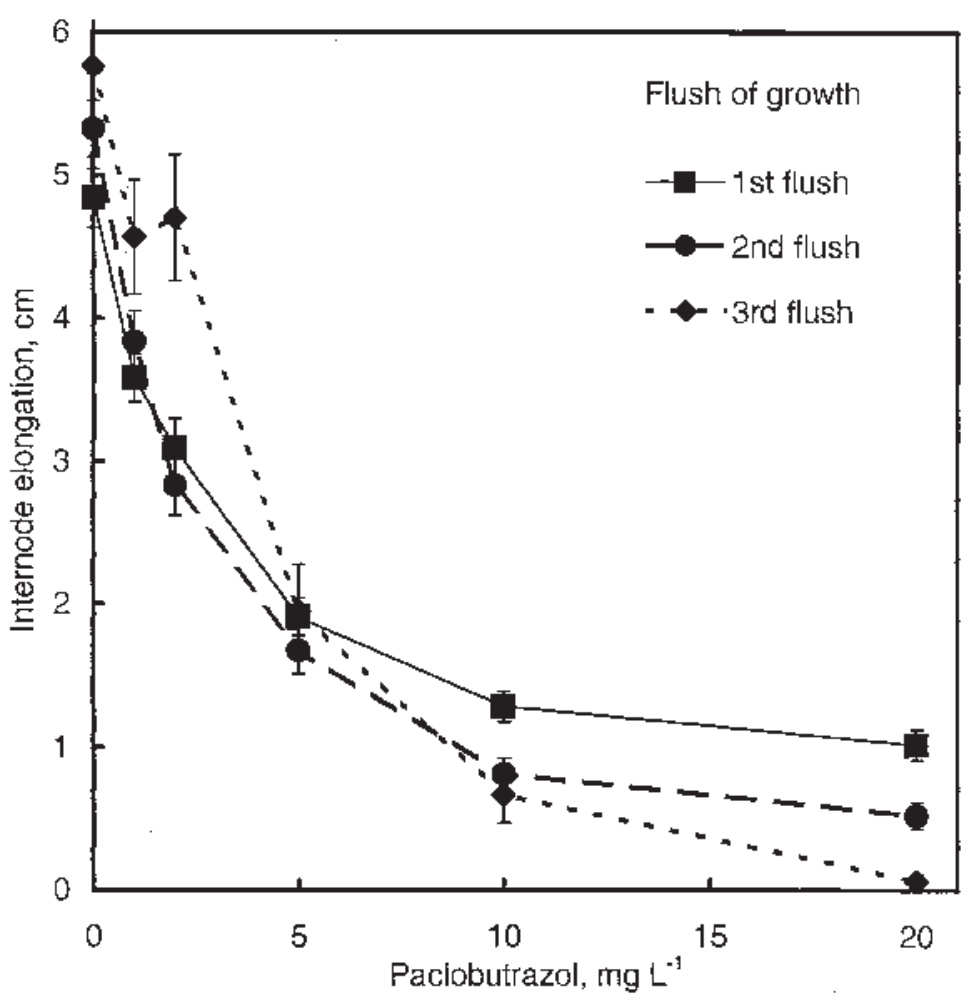

Fig. 4. Elongation of each flush of growth of rhododendron in 1999 as a function of paclobutrazol concentration. Symbols are averages over four cultivars, and error bars indicate standard error of estimate from analysis of variance.
Treatments in 1999: Stem elongation. There was no stem elongation until a month after the application of paclobutrazol in Apr. 1999. The three flushes of growth were completed by mid-June, early August, and late September. Treatment with paclobutrazol at concentrations as low as $1 \mathrm{mg} \cdot \mathrm{L}^{-1}$ decreased plant height (Fig. 3). Stem elongation decreased linearly with increasing paclobutrazol concentration up to 5 $\mathrm{mg} \cdot \mathrm{L}^{-1}$. The effect on plant height was similar at 10 and $20 \mathrm{mg} \cdot \mathrm{L}^{-1}$. Cultivars differed in total stem elongation, and in response to concentration of paclobutrazol (Table 2). Among untreated plants, 'Nova zembla' had the shortest total stem elongation, $13.4 \mathrm{~cm}$; the other cultivars grew 16.5 to $17 \mathrm{~cm}$. The cultivars differed most in elongation of the third flush of growth (data not shown). Both linear and quadratic terms in concentration had significant effects on elongation of each flush of growth (Table 2). Fig. 3 shows the fit of total stem elongation to the inverse relationship described by [Eq. 1]. This equation indicated the concentration of paclobutrazol for half-maximal effect $\left(\mathrm{K}_{\mathrm{C}}\right)$ varied between cultivars: $2.2,4.3,1.6$, and 1.8 $\mathrm{mg} \cdot \mathrm{L}^{-1}$, for 'Boursault', 'Cunninghams white', 'Novazembla', and 'Roseum elegans', respectively. 'Cunninghams white' differed from the other cultivars primarily due to earlier growth and response of the first and second flushes to paclobutrazol.

The effect of paclobutrazol differed for each flush of growth. The third flush of growth was less affected by a low dose of paclobutrazol than earlier flushes, whereas at higher doses the second and third flush were inhibited more than the first flush (Fig. 4). Thus, paclobutrazol at 1.0 and $2.0 \mathrm{mg} \cdot \mathrm{L}^{-1}$ provided a temporary inhibition of growth, whereas a concentration of $10 \mathrm{or} 20 \mathrm{mg} \cdot \mathrm{L}^{-1}$ appeared to inhibit growth more completely as the season progressed.

Effect on number of flower buds. Cultivars differed in the number of flower buds, and except for 'Boursault', the number of flower buds increased with paclobutrazol concentration up to $10 \mathrm{mg} \cdot \mathrm{L}^{-1}$ (Fig. 5). Flowering of 'Nova zembla' was most responsive to paclobutrazol, with a response at $1 \mathrm{mg} \cdot \mathrm{L}^{-1}$. While most cultivars had a similar number of flower buds after applications of paclobutrazol at 5 , 10 , or $20 \mathrm{mg} \cdot \mathrm{L}^{-1}$, 'Cunninghams white' had only 2.4 buds at $20 \mathrm{mg} \cdot \mathrm{L}^{-1}$, compared to 4.4 buds at $10 \mathrm{mg} \cdot \mathrm{L}^{-1}$. 'Nova zembla' had more flower buds in response to paclobutrazol in 1999 than in 1998, while the responses of 'Boursault' and 'Roseum elegans' were less in 1999 than in 1998.

\section{Discussion}

Paclobutrazol had a persistent effect on stem elongation of rhododendron, in contrast to the recovery of growth of herbaceous plants. The latter generally grow out of the effect of an application of growth retardant in 4 to 6 weeks (Fisher et al., 1996; Keever and Foster, 1994; Latimer and Baden, 1992; Tayama and Carver, 1992). The response of rhododendron to a high dose of paclobutrazol decreases more slowly with time, over a period of years (Gent, 1997; 


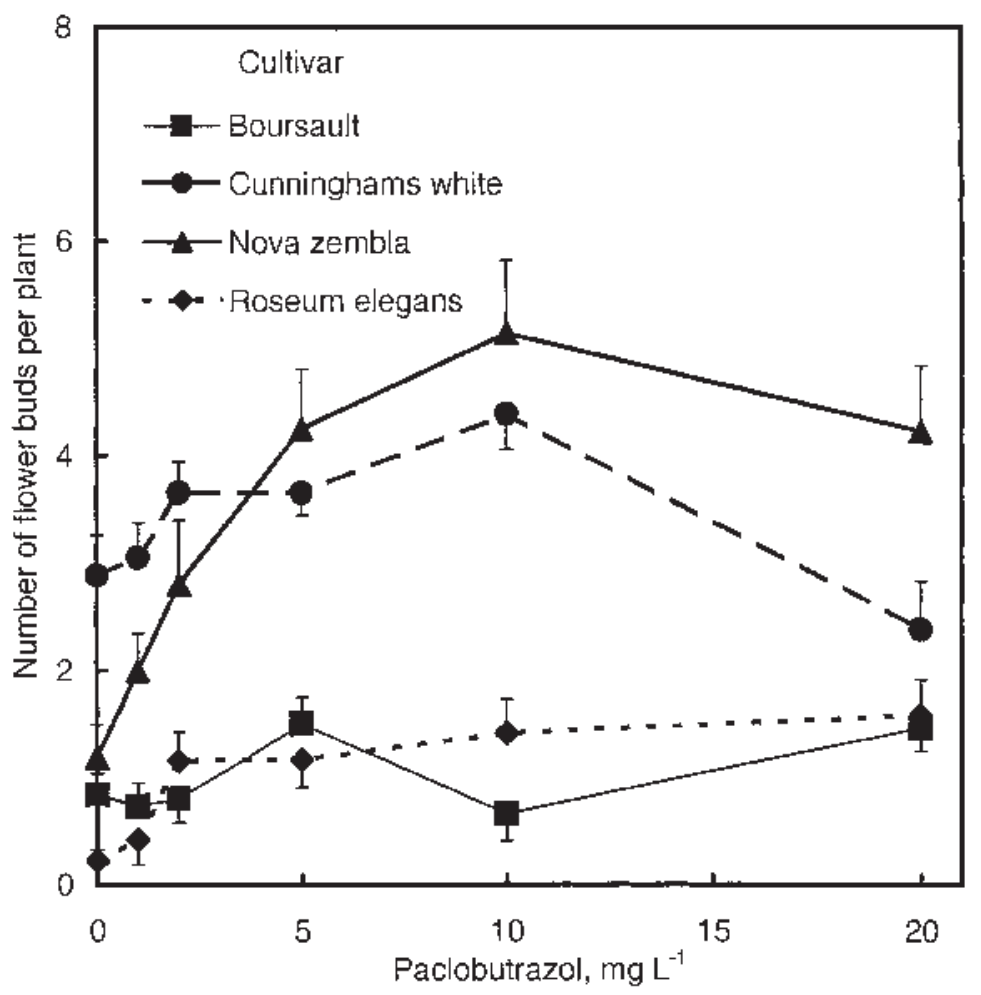

Fig. 5. Number of flower buds per rhododendron plant in 1999 as a function of paclobutrazol concentration. Symbols represent each of four cultivars, and error bars indicate standard error of estimate.

Ranney et al., 1994; Wilkinson and Richards, 1992). However, there was no simple time dependence to explain the effect of date of application of paclobutrazol on internode elongation of individual flushes of growth of rhododendron within one growing season. Internode elongation recovered for the third flush if plants were treated with paclobutrazol at 1 or $2 \mathrm{mg} \cdot \mathrm{L}^{-1}$ early in the season, but, the inhibition of elongation became more complete as the season progressed for plants treated with 10 or $20 \mathrm{mg} \cdot \mathrm{L}^{-1}$. Thus, biomass dilution does not seem to explain the time dependence of inhibition of stem elongation of rhododendron within a growing season, at least if the dose inhibited more than half the stem elongation of controls.

If applied to cuttings before transplant, a paclobutrazol concentration of $20 \mathrm{mg} \cdot \mathrm{L}^{-1}$, a dose of $0.8 \mathrm{mg} /$ plant, almost completely inhibited internode elongation of the third flush in both years of this study. A similar dose applied in the same volume to a 1-gal pot in July had much less effect (Fig. 2). A dose of $7 \mathrm{mg} /$ plant was required to inhibit more than half the stem elongation of rhododendron once transplanted to a larger pot (Ranney et al., 1994). Thus, application to rooted cuttings has more efficacy than application after transplant. Binding to the root medium (Million et al., 1998; 1999) likely plays a role in the decreased efficacy of paclobutrazol applied after transplant. The greater volume of root medium would bind a greater fraction of growth retardant applied.

Growth retardant and environment are factors that are likely to co-limit stem elongation. A low concentration of paclobutrazol may have little effect when other factors inhibit stem elongation, but would limit elongation under conditions that otherwise lead to excessive growth. If the goal is to insure against extreme stem elongation, then paclobutrazol at a concentration of $2 \mathrm{mg} \cdot \mathrm{L}^{-1}$ $(0.08 \mathrm{mg} /$ plant $)$ may be sufficient when applied as a drench to rooted cuttings or liners before transplant. This concentration inhibited trial. However, the inhibition was only half the maximum inhibition of stem elongation, and internode elongation recovered by the third flush of growth.

\section{Literature Cited}

Barrett, J.E. 1982. Chrysanthemum height control by ancymidol, PP333, and EL500 dependent on medium composition. HortScience 17: 896-897.

Bearce, B.C. and S. Singha. 1992. Response of poinsettia to preplant root-zone soaks in uniconazole. HortScience 27:1228.

Dicks, J.W. and D.A. CharlesEdwards. 1973. Aquantitative description of inhibition of stem growth in vegetative lateral shoots of Chrysanthemum morifolium by $N$-dimethylaminosuccinamic acid stem growth significantly in both years of this (daminozide). Planta 112:71-82.

Fisher,P.R.,R.D. Heins, and J.HLieth. 1996. Modeling the stem elongation response of poinsettia to chlormequat. J. Amer. Soc. Hort. Sci. 121: 861-868.

Gent, M.P.N. 1995. Paclobutrazol or uniconazole applied early in the previous season promote flowering of field grown Rhododendron and Kalmia. J. Plant Growth Regulat. 14:205-210.

Gent, M.P.N. 1997. Persistence of triazole growth retardants on stem elongation of Rhododendron and Kalmia. J. Plant Growth Regulat.16: 197-203.

Gent, M.P.N. and R.J. McAvoy. 2000. Plant growth retardants in ornamental horticulture, p. 89-146. In: A.S. Basra (ed.). Plant growth retardants in agriculture and horticulture: Their role and commercial uses. Food Prod. Press, Binghamton, N.Y.

Kawabata, O. and J. DeFrank. 1994. A flexible function for regressing asymptotically declining responses of plant growth to growth retardants. HortScience 29:1357-1359.

Keever, G.A. and W.J. Foster. 1991. Production and post-production performance of uniconazole treated bedding plants. J. Environ. Hort. 9:203-206.

Latimer, J.C. and S.A. Baden. 1994. Persistent effects of plant growth regulators on landscape performance of seed geraniums. J. Environ. Hort. 12:150-154.

Million, J.B., J.E. Barrett, T.A. Nell, and D.G. Clark. 1998. Influence of media components on efficacy of paclobutrazol in inhibiting growth of brocolli and petunia. HortScience 33:852-856.

Million, J.B., J.E. Barrett, T.A. Nell, and D.G. Clark. 1999. Paclobutrazol distribution following application to two media as determined by bioassay. HortScience 34:1099-1102.

Newman, S.E. and J.S. Tant. 1995. Root-zone medium influences growth of poinsettias treated with paclobutrazol-impregnated spikes and drenches. HortScience 30:1403-1405.

Ranney, T.G., R.E. Bir, J.L. Conner, and E.P. Whitman. 1994. Use of paclobutrazol to regulate shoot growth and flower development of 'Roseum elegans' Rhododendron. J. Environ. Hort. 12:174-178.

Reynolds, A.G. and D.A. Wardle. 1990. Vegetative growth suppression by paclobutrazol in greenhouse grown 'Pinot Noir' grapevines. HortScience 25:1250-1254.

Sanderson, K.C., W.C. Martin, and J. McGuire. 1988. Comparison of paclobutrazol tablets, drenches, gels, capsules, and sprays on chrysanthemum growth. HortScience 23:1008-1009.

Schuch, U.K. 1994. Response of Chrysanthemum to uniconazole and daminozide applied as a dip to cuttings or as a foliar spray. J. Plant Growth Regulat. 13:115-121.

Tayama, H.K. and S.A. Carver. 1992. Residual efficacy of uniconazole and daminozide on potted 'Bright Golden Anne' Chrysanthemum. HortScience 27:124-125.

Warren, S.L., F.A. Blazich, and M. Thetford. 1991. Whole plant responses of selected woody landscape species to uniconazole. J. Environ. Hort. 9:163-167.

Wilkinson, R.I. and D. Richards. 1991. Influence of paclobutrazol on growth and flowering of Rhododendron 'Sir Robert Peel'. HortScience 26:282-284. 